\title{
Expression profiles of growth hormone receptor and insulin-like growth factor I in cattle and yak tissues revealed by quantitative real-time PCR
}

\author{
Jie Pei ${ }^{1,2}$, Xia Lang ${ }^{1,2}$, Xian Guo ${ }^{1,2}$, Pengjia Bao ${ }^{1,2}$, Chunnian Liang ${ }^{1,2}$, Min Chu ${ }^{1,2}$, Ruilin \\ Feng ${ }^{1}$ and Ping Yan ${ }^{1,2}$ \\ 'Lanzhou Institute of Husbandry and Pharmaceutical Sciences, Chinese Academy of Agricultural Sciences, Lanzhou, \\ China, ${ }^{2}$ Key Laboratory of Yak Breeding Engineering in Gansu Province, Lanzhou, China
}

\section{Abstract}

The goals of this study were to compare the mRNA expression profiles of growth hormone receptor (GHR) and insulin-like growth factor I (IGF-I) in various tissues of cattle and the semi-wild yak (Datong yak) and to find out whether the mRNA levels of the two genes are correlated. The mRNA levels of GHR and IGF-I in heart, lung, liver, spleen, pancreas, kidney, muscle, mammary gland and ovary of cattle and yak were investigated by using quantitative real-time polymerase chain reaction $(P C R)$. The experiments showed that the transcript levels of the two genes were significantly higher in liver $(P<0.05)$ than in the other tissues for both species and that IGF-I levels varied more among tissues $(P<0.01)$ than did GHR levels. The GHR transcript level in pancreas was higher in yak $(P<0.05)$ than in cattle. There was no statistically significant difference in IGF-I transcript levels among all the tissues of both bovine groups. Growth hormone receptor and IGF-I transcript levels were positively correlated in mammary gland $(P<0.01)$, lung $(P<0.05)$ and muscle $(P<0.05)$ in yak, negatively correlated in cattle heart $(P<0.05)$ and not correlated in the other tissues. The results indicate that the two genes are regulated differently in various tissues under normal physiological conditions in these two bovine species.

Keywords: cattle, yak, growth hormone receptor, insulin-like growth factor-I, quantitative real-time PCR

Abbreviations: ACTB: actin-beta, GAPDH: glyceraldehyde-3-phosphate-dehydrogenase, GH: growth hormone, GHR: growth hormone receptor, IGF-I: insulin-like growth factor I, PCR: polymerase chain reaction

Archiv Tierzucht 56 (2013) 70, 700-708

doi: $10.7482 / 0003-9438-56-070$

Corresponding author:

Ping Yan; email: pingyan63@126.com

Lanzhou Institute of Husbandry and Pharmaceutical Sciences, Chinese Academy of Agricultural Sciences, 335 Jiangouyan

ST, Qilihe District, Lanzhou, Gansu, 730050, China

() 2013 by the authors; licensee Leibniz Institute for Farm Animal Biology (FBN), Dummerstorf, Germany. This is an Open Access article distributed under the terms and conditions of the Creative Commons Attribution 3.0 License (http://creativecommons.org/licenses/by/3.0/). 


\section{Introduction}

The GH (growth hormone)-IGF-I (insulin-like growth factor I) axis, also known as the somatotrophic axis, is significant for metabolic control (Dominici et al. 2005). In the somatotrophic axis, circulating $\mathrm{GH}$ binds to the extracellular domain of the growth hormone receptor (GHR), which is expressed in all tissues especially in the liver (Ahmed et al. 2010). The GHR is a transmembrane glycoprotein that belongs to the cytokine receptor superfamily. Growth hormone binding to the GHR leads to the physiological functions of the hormone and affects multiple metabolic pathways and cellular events such as cell proliferation, differentiation, regulation of growth and metabolic processes including glucose uptake and protein metabolism (Dominici et al. 2005, Casanueva 1992, Zhang \& Ho 2011).

Growth hormone secreted from the pituitary acts both directly and indirectly through induction of IGF-I to promote tissue growth and regulate metabolism (Lobie et al. 2000, Frystyk 2004). Growth hormone induces IGF-I expression in the liver and peripheral target tissues but it is hepatic-derived IGF-I that accounts for most of the circulating IGF-I (Le Roith et al. 2001). Insulin-like growth factor $I$ is regarded as the most sensitive marker of GH secretory status in both GH-deficient patients and acromegalics. In addition, serum IGF-I levels show strong correlation with administered GH dose in GH-deficient patients (de Boer et al. 1996).

The yak (Bos grunniens) inhabits steppes on the Qinghai-Tibetan Plateau of the Himalayan highlands and is the only bovine species adapted to a harsh environment at high altitudes (3000-5000 m) with low oxygen, severely cold winters and short growing seasons for herbage (Wiener et al. 2003).

The adaptability of the yak is obviously strong compared with cattle. It is vital to comprehend the relationship between genes and growth in cattle and yak. The GHR and IGF-I are the primary genes for growth and development. That is why describing the contributions of GHR and IGF-I genes to development may enhance our understanding of the different mechanisms dominating growth and development in these two bovine species and lead to the production of improved cattle. To the best of our knowledge, there are no published comparative data on GHR and IGF-I expression in yak and cattle. In this study, GHR and IGF-I expression in various tissues of these two bovine species are described and the correlation of their expression across species and tissues is tested.

\section{Material and methods}

\section{$R N A$ isolation and reverse transcription}

Various tissues were collected from 10 cattle and 10 yaks. All animals were adult (more than 4 years old) and unrelated to one another. They were selected at random from the Gannan yak farm of Gan Su province at an altitude of $3000 \mathrm{~m}$ above sea level. They were considered as biological replicates and were all in a good health status without supplementary feeding or fattening. After slaughter, a sample of the same region of the heart, lung, liver, spleen, pancreas, kidney, muscle, mammary gland and ovary was taken from each experimental animal, immediately frozen in liquid nitrogen, crushed to powder on the same day and stored at $-80^{\circ} \mathrm{C}$. Total RNA was extracted using Invitrogen TRIzol (Life Technologies, Carlsbad, CA, USA) according to the manufacturer's instructions. A fraction of the RNA was 
DNase-treated using a Ambion DNA free kit (Life Technologies, Carlsbad, CA, USA). The RNA concentration and OD260/280 ratio of the samples were then measured with a NanoDrop 2000 Spectrophotometer (Thermo Fisher Scientific, Waltham, MA, USA) giving values between 600 and $5000 \mathrm{ng} / \mathrm{ml}$ and between 1.9 and 2.1, respectively. Ribonucleic acid quality was assessed by evaluation of the $28 \mathrm{~S}$ and the $18 \mathrm{~S}$ ribosomal bands on a $1.2 \%$ agarose electrophoretic gel. Each RNA sample was diluted to $500 \mathrm{ng} / \mathrm{ml}$ and reverse transcribed by using a PrimeScript RT reagent Kit (Takara Bio, Otsu, Japan).

\section{Primer design}

Complete mRNA sequences of GAPDH (glyceraldehyde-3-phosphate dehydrogenase, EU195062) and ACTB ( $\beta$-actin, DQ838049) from yak have been previously deposited in GenBank. For GHR and IGF-I, whose yak mRNA sequences are not available, coding regions from bovine GHR (NM_176608) and IGF-I (NM_001077828) were used to design primers. Using the Primer v. 5.0 software (Primer-E Ltd, Lutton, UK) primer pairs were designed to generate short amplicons of 80-150 base pairs (bp) spanning at least two exons and avoiding sequence polymorphisms between cattle and yak. Dimer-forming primers were avoided by using Mfold (http://mfold.rna.albany.edu/?q=mfold) (Zuker 2003). The primers are described in Table 1. The identity of PCR products was evaluated by sequencing using M13 forward and reverse primers.

Table 1

Primers used for quantitative real-time PCR

\begin{tabular}{|c|c|c|c|c|}
\hline $\begin{array}{l}\text { Gene } \\
\text { Symbol }\end{array}$ & $\begin{array}{l}\text { Forward primer }\left(5^{\prime}-3^{\prime}\right) \\
\text { Reverse primer }\left(5^{\prime}-3^{\prime}\right)\end{array}$ & $\begin{array}{l}\text { Primer } \\
\text { Position* }\end{array}$ & $\begin{array}{l}\text { Primer } \\
\text { length }\end{array}$ & $\mathrm{T},{ }^{\circ} \mathrm{C}$ \\
\hline \multirow{2}{*}{ GAPDH } & Forward primer: CCACGAGAAGTATAACAACACC & 408 & 22 & 54.4 \\
\hline & Reverse primer: GTCATAAGTCCCTCCACGAT & 527 & 20 & 53.6 \\
\hline \multirow{2}{*}{ ACTB } & Forward primer: TCTTCCAGCCTTCCTTCCT & 782 & 19 & 56.7 \\
\hline & Reverse primer: CCGTGTTGGCGTAGAGGT & 892 & 18 & 56.2 \\
\hline \multirow{2}{*}{ GHR } & Forward primer: AACCACCACCCAATACAG & 552 & 18 & 55.1 \\
\hline & Reverse primer: CAACGAGTACATCGGAAC & 685 & 18 & 54.2 \\
\hline \multirow{2}{*}{ IGF-I } & Forward primer: AGCAGTCTTCCAACCCAA & 212 & 18 & 53.9 \\
\hline & Reverse primer: AGATGCGAGGAGGATGTG & 297 & 18 & 53.8 \\
\hline
\end{tabular}

*The positions are numbered according to the sequences in GenBank

\section{Standard curves}

Standard curves were used to assess the amplification efficiency of each primer. Polymerase chain reaction was performed using the SYBR Premix Ex TaqTM II (Takara Bio, Otsu, Japan) with the primers from Table 1. In all PCRs, each primer was used at $20 \mu \mathrm{M}$. An 8-point 2 -fold dilution series was included in every run to create a relative standard curve used for calculating PCR efficiency. Reaction conditions were as follows: $95^{\circ} \mathrm{C}$ for $30 \mathrm{~s}$, then 40 cycles of $95^{\circ} \mathrm{C}$ for $5 \mathrm{~s}$ and $56^{\circ} \mathrm{C}$ for $20 \mathrm{~s}$, respectively. Reactions were run on a CFX96TM Real-Time 
System (Bio-Rad, Hercules, CA, USA). Parallel reactions were performed in triplicate for every cDNA sample. A template-free control and a sample without reverse transcriptase were included in each amplification run. The absence of primer dimers was verified by melting curve analysis and by $4 \%$ agarose gel electrophoresis. Standard curves were analysed using the CFX96TM Real-Time System.

\section{Real-time quantitative $P C R$ assays}

One sample was randomly selected as the control and was present in each PCR reaction plate. Polymerase chain reactions were prepared with $10 \mu$ l Power SYBR Premix Ex TaqTM II with a final concentration of $400 \mathrm{nM}$ of each primer and $5 \mu \mathrm{l}$ of template diluted $1: 50$ in a total reaction volume of $20 \mu$. Using the cycling conditions described above, the reactions for these genes were performed in triplicate in three independent runs.

\section{Statistical analysis}

The relative quantities obtained from the PCRs were normalized by dividing the raw gene expression data by the normalization factor, the geometric mean of the raw expression data of the two most stable reference genes. Based on the standard curves for each gene, the samples' cDNA copy numbers were calculated according to the quantitative mean of each sample. Finally, each of the calculated copy numbers for the genes of interest was normalized against the corresponding GAPDH and ACTB copy numbers.

Relative expression levels were calculated using the following formula:

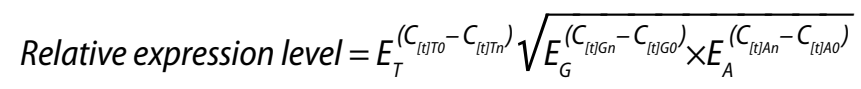

where $E_{G}$ is the amplification efficiency of GAPDH gene, $E_{A}$ is the amplification efficiency of $A C T B$ gene, $E_{T}$ is the amplification efficiency of target gene, $C_{(t) G 0}$ is the $G A P D H C_{(t)}$ of control sample, $C_{(t) G n}$ is the $G A P D H C_{(t)}$ of number $n$ sample, $C_{(t) A}$ is the $A C T B C_{(t)}$ of control sample, $C_{(t) A n}$ is the $A C T B C_{(t)}$ of number $n$ sample, $C_{(t) T 0}$ is the unknown gene $C_{(t)}$ of control sample and $C_{(t) T n}$ is the unknown gene $C_{(t)}$ of number $n$ sample.

For all statistical analyses, these normalized expression data were converted to logarithmic values in order to obtain symmetrical data. Two freely available software tools, geNorm (http://medgen.ugent.be/ jvdesomp/genorm/index.php) and NormFinder (http://moma. $\mathrm{dk} /$ normfinder-software), were used to evaluate the stability of expression of two reference genes and quantities transformed to a linear scale (the highest relative quantity for each gene was set to 1) were used as input data.

All gene expression data were subjected to the independent-samples t-test and Spearman nonparametric correlation test using the SPSS 16.0 for Windows (SPSS Inc., Chicago, IL, USA). Values of $P<0.05$ were considered statistically significant and $P<0.01$ were considered highly statistically significant. 


\section{Results}

\section{Calculation of PCR efficiency}

The amplification efficiency of each PCR assay was calculated using serial dilutions of each template and ranged from $197.2 \%$ to $215.6 \%$ (Table 2). Primer dimers were absent in all reactions.

Table 2

The characteristics of the amplicons produced

\begin{tabular}{lccccc}
\hline $\begin{array}{l}\text { Gene } \\
\text { Symbol }\end{array}$ & $\begin{array}{c}\text { Exons } \\
\text { spaned }\end{array}$ & $\begin{array}{c}\text { Amplicon } \\
\text { length }\end{array}$ & $\begin{array}{c}\text { Amplicon } \\
\mathrm{Tm}\end{array}$ & $\begin{array}{c}\text { Amplification } \\
\text { efficiency }\end{array}$ & $\begin{array}{c}\text { Genbank } \\
\text { number }\end{array}$ \\
\hline GAPDH & $4,5,6$ & 120 & $85.0^{\circ} \mathrm{C}$ & $197.2 \%$ & $\mathrm{HQ231767}$ \\
ACTB & 2,3 & 111 & $83.5^{\circ} \mathrm{C}$ & $202.3 \%$ & $\mathrm{HQ231765}$ \\
GHR & 5,6 & 134 & $79.5^{\circ} \mathrm{C}$ & $214.6 \%$ & $\mathrm{HQ} 231768$ \\
IGF-I & 1,2 & 86 & $80.0^{\circ} \mathrm{C}$ & $215.6 \%$ & $\mathrm{HQ231770}$ \\
\hline
\end{tabular}

\section{GHR and IGF-I mRNA expression patterns}

Transcript levels of GHR and IGF-I were quantified using GAPDH and ACTB as internal reference genes in the nine tissues from cattle and yak. The variation in IGF-I transcript levels was larger $(P<0.01)$ than that for GHR in the various tissues in the two species (Figure 1). In both species, the GHR and IGF-I mRNA levels were significantly higher in liver $(P<0.05)$ than in the other tissues, the GHR transcript level was lowest $(P<0.05)$ in heart and the lowest IGF-I transcript level was seen in muscle. The GHR transcript level in pancreas in the yak group was higher $(P<0.05)$ than that in the cattle group. There was no other statistically significant difference between cattle and yak. Insulin-like growth factor I mRNA levels in the various tissues did not differ between the two bovine groups.

\section{Correlation between GHR and IGF-I transcript levels}

The GHR and IGF-I transcript profiles in the different cattle and yak tissues were analysed using Pearson's correlation coefficient. Positive correlations were found between GHR and IGF-I transcript levels in mammary gland (Pearson Correlation $=0.991, P<0.01$ ), muscle (Pearson Correlation $=0.823, P<0.05$ ) and lung (Pearson Correlation=0.779, $P<0.01$ ) in yak and a negative correlation was found between GHR and IGF-I transcript levels in the heart (Pearson Correlation $=-0.735, P<0.05$ ) in cattle.

\section{Discussion}

In view of the important role of the GHR and IGF-I genes in growth and development, the goals of the present study were to describe the mRNA expression profiles of these two genes in cattle and yak and explore the relationship between them in various tissues of the two species. Under normal physiological conditions, the synthesis of any component of the organism should be equal to the amount of it required (Smith \& Chapman 2010), so translational and transcript levels for most of the genes should be equal too. Meanwhile, 

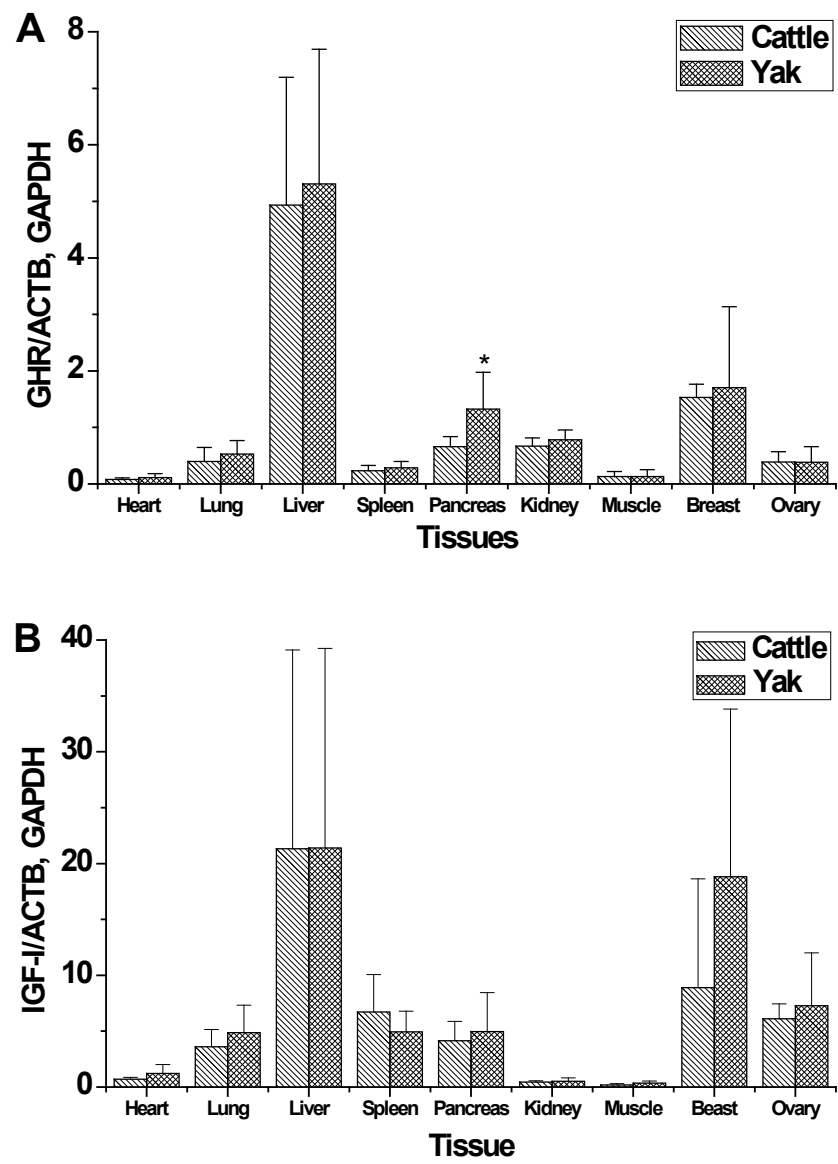

A. GHR mRNA relative expression level.

B. IGF-I mRNA relative expression level. Asterisks indicate differences between the two bovine species that are statistically significant $\left({ }^{*} P<0.05\right)$.

All results were normalized against the expression of GAPDH and ACTB. Error bars are $\pm \operatorname{SEM}(n=10)$.

Figure 1

Transcript levels of GHR and IGF-I analyzed by quantitative real-time $P C R$ in heart, lung, liver, spleen, pancreas, kidney, muscle, mammary gland, and ovary of cattle and yak.

decreased serum IGF-I is related to reduced liver IGF-I mRNA in food-deprived cattle (Wang et al. 2003). Thus, the mRNA levels of the IGF-I and GHR genes may reflect to some extent the GHR and IGF-I concentrations in different tissues of the yak. We used GAPDH and ACTB as two internal references for quantitative real-time PCR measurements of the transcript levels of GHR and IGF-I because using two internal references is more reliable than using only one.

The GHR and IGF-I mRNA expression vary in different animal tissues. For example, GH stimulates IGF-I mRNA expression in liver, semitendinosus muscle and adipose tissue but not in longissimus muscle and regulates GHR mRNA in liver and skeletal muscle but not in adipose tissue (Rhoads et al. 2007). In the present study, the GHR and IGF-I mRNA levels in various tissues of cattle and yak are described. Both genes were highest expressed in liver. The highest GHR and IGF-I mRNA concentrations were found in liver in accordance with previous studies related to several mammals (Lucy et al. 1998, Han et al. 1987, Liu et al. 2000). Our measurements of GHR and IGF-I mRNA levels in cattle and yak show that different tissues need different amounts of these two growth factors for growth.

Plasma GH is known to cause the release of hepatic IGF-I into the blood stream and this accounts for $75 \%$ of circulating IGF-I. However, liver IGF-I is not important for growth since conditional disruption of the liver IGF-I gene does not result in a reduction in mouse size 
even when IGF-I is depressed by $75 \%$ (Yakar et al. 1999). Liver-specific knockout of IGF-I, although dramatically lowering serum IGF-I levels, does not prevent normal growth, suggesting that autocrine/paracrine IGF-I (rather than liver-derived IGF-I) may predominate for normal postnatal growth (Yakar et al. 1999, Sjögren et al. 1999). The GHR is located at the cell membrane and executes signal transmission functions from $\mathrm{GH}$. Its transcription and translation are completed by the local cell, in whose membrane GHR is situated. This study showed that the transcript level of GHR in the pancreas is higher in yak than in cattle. This result suggests that the pancreas may have a higher metabolic rate in yak than in cattle.

Growth hormone plays an important role in the regulation of GHR and IGF-I and it may link the actions of the GHR and IGF-I genes (Dominici et al. 2005, Sotelo et al. 1998). Growth hormone has been shown to regulate the steady-state level of IGF-I mRNA in both hepatic and extra-hepatic tissues and IGF-I production is dependent on GH and the presence of GHR that are abundant in postnatal liver (Huang et al. 2004). Growth hormone binding to GHR in the liver activates a signalling pathway that culminates in IGF-I gene transcription (Netchine et al. 2011). The circulating levels of GH augment muscle IGF-I protein expression only in the presence of an intact GHR but the absence of a functional GHR does not affect basal levels of muscle IGF-I protein in female mice. In patients with the d3-allele, even treated with a similar mean GH dose, individuals carrying at least one GHR d3-allele reached higher IGF-I levels than those homozygous for the full-length allele (Glad et al. 2010). Growth hormone can also affect the expression level of GHR. Growth hormone deficiency was associated with diminished body weight and GHR expression, while increased GH concentration led to increased GHR expression (González et al. 2007).

The above research results suggest that the mRNA expression levels of GHR and IGF-I may be closely correlated and that there is a molecular pathway regulating the genes' interaction. The analysis of transcript levels in nine different tissues indicated that GHR and IGF-I expression are positively correlated in mammary gland, muscle and lung of yak under normal physiological conditions. This suggests that these three tissues have more rapid metabolism rates than other tissues in the yak. The yak may adapt to the harsh environment at high altitudes with low oxygen and severely cold winters on the Qinghai-Tibetan Plateau through the special function of these three tissues. To our surprise, mRNA levels of the two genes were negatively correlated in cattle heart. This is probably due to a differential regulation of GHR and IGF-I mRNA expression among different tissues at different developmental stages and according to physiological status (Jiang \& Lucy 2001).

The IGF-I concentration of each tissue comprises two main parts, plasma IGF-I from liver and local IGF-I from the tissue itself. Circulating GH appears to be involved only in the augmentation of resting muscle IGF-I protein concentrations and not in the maintenance of basal muscle IGF-I protein levels (Micke et al. 2011). Another possibility is that the transcript levels of GHR and IGF-I are not regulated by the same pathway. A report of the effect of the combined knockout of the GHR and IGF-I genes compared with the individual knockouts of each suggested that GH and IGF-I may contribute independently to growth in the mouse (Lupu et al. 2001).

In conclusion, we have described the total mRNA transcript profiles for GHR and IGF-I in nine tissues of cattle and yak by using real-time PCR and have analysed the correlation of the two genes' expression profiles in these tissues. The results suggest that there may be a real relationship between the supply of and requirement for GHR and IGF-I during 
the growth and development of the yak and different regulatory mechanisms in different tissues of cattle and yak.

\section{Acknowledgements}

The research was supported by »the Great Project of Science and Technology of Gansu Province in China (1102NKDA027)«, and »the Fundamental Research Funds for the Central Public Welfare Research Institutes (1610322012003)«.

\section{References}

Ahmed SF, Farquharson C (2010) The effect of GH and IGF1 on linear growth and skeletal development and their modulation by SOCS proteins. J Endocrinol 206, 249-259

Casanueva FF (1992) Physiology of growth hormone secretion and action. Endocrinol Metab Clin North Am 21, 483-517

De Boer H, Blok GJ, Popp-Snijders C, Stuurman L, Baxter RC, van der Veen E (1996) Monitoring of growth hormone replacement therapy in adults, based on measurement of serum markers. J Clin Endocrinol Metab 81, 1371-1377

Dominici FP, Argentino DP, Muñoz MC, Miquet JG, Sotelo Al, Turyn D (2005) Influence of the crosstalk between growth hormone and insulin signalling on the modulation of insulin sensitivity. Growth Horm IGF Res 15, 324-336

Frystyk J (2004) Free insulin-like growth factors - measurements and relationships to growth hormone secretion and glucose homeostasis. Growth Horm IGF Res 14, 337-375

Glad CAM, Johannsson G, Carlsson LMS, Svensson PA (2010) Rapid and high throughput genotyping of the growth hormone receptor exon 3 deleted/full-length polymorphism using a tag SNP. Growth Horm IGF Res 20, 270-273

González L, Curto LM, Miquet JG, Bartke A, Turyn D, Sotelo Al (2007) Differential regulation of membrane associated-growth hormone binding protein (MA-GHBP) and growth hormone receptor (GHR) expression by growth hormone (GH) in mouse liver. Growth Horm IGF Res 17, 104-112

Han VK, D'Ercole AJ, Lund PK (1987) Cellular localization of somatomedin (insulin-like growth factor) messenger RNA in the human fetus. Science 236, 193-197

Huang Y, Kim SO, Yang N, Jiang J, Frank SJ (2004) Physical and Functional Interaction of Growth Hormone and Insulin-Like Growth Factor-I Signaling Elements. Mol Endocrinol 18, 1471-1485

Jiang H, Lucy MC (2001) Variants of the 5'-untranslated region of the bovine growth hormone receptor mRNA: isolation, expression and effects on translational efficiency. Gene 265, 45-53

Le Roith D, Bondy C, Yakar S, Liu JL, Butler A (2001) The Somatomedin Hypothesis: 2001. Endocr Rev 22, 53-74

Liu JL, Yakar S, LeRoith D (2000) Conditional Knockout of Mouse Insulin-Like Growth Factor-1 Gene Using the Cre/loxP System. Proc Soc Exp B 223, 344-351

Lobie PE, Zhu T, Graichen R, Goh ELK (2000) Growth hormone, insulin-like growthfactor I and the CNS: Localization, function and mechanism of action. Growth Horm IGF Res 10 (Suppl.), S51-S56

Lucy MC, Boyd CK, Koenigsfeld AT, Okamura CS (1998) Expression of Somatotropin Receptor Messenger Ribonucleic Acid in Bovine Tissues. J Dairy Sci 81, 1889-1895

Lupu F, Terwilliger JD, Lee K, Segre GV, Efstratiadis A (2001) Roles of Growth Hormone and Insulin-like Growth Factor 1 in Mouse Postnatal Growth. Dev Biol 229, 141-162

Micke GC, Sullivan TM, McMillen IC, Gentili S, Perry VEA (2011) Protein intake during gestation affects postnatal bovine skeletal muscle growth and relative expression of IGF1, IGF1R, IGF2 and IGF2R. Mol Cell Endocrinol $332,234-241$ 
Netchine I, Azzi S, Le Bouc Y, Savage MO (2011) IGF1 molecular anomalies demonstrate its critical role in fetal, postnatal growth and brain development. Best Pract Res Clin Endocrinol Metab 25, 181-190

Rhoads RP, Kim JW, van Amburgh ME, Ehrhardt RA, Frank SJ, Boisclair YR (2007) Effect of nutrition on the GH responsiveness of liver and adipose tissue in dairy cows. J Endocrinol 195, 49-58

Sjögren K, Liu JL, Blad K, Skrtic S, Vidal O, Wallenius V, LeRoith D, Törnell J, Isaksson OGP, Jansson JO, Ohlsson C (1999) Liver-derived insulin-like growth factor I (IGF-I) is the principal source of IGF-I in blood but is not required for postnatal body growth in mice. Proc Natl Acad Sci U S A 96, 7088-7092

Smith DR, Chapman MR (2010) Economical Evolution: Microbes Reduce the Synthetic Cost of Extracellular Proteins. MBio 1, e00131-10

Sotelo Al, Bartke A, Kopchick JJ, Knapp JR, Turyn D (1998) Growth hormone (GH) receptors, binding proteins and IGF-I concentrations in the serum of transgenic mice expressing bovine $\mathrm{GH}$ agonist and antagonist. J Endocrinol 158, 53-59

Wang Y, Eleswarapu S, Beal WE, Swecker Jr WS, Akers RM, Jiang H (2003) Reduced Serum Insulin-Like Growth Factor (IGF) I Is Associated with Reduced Liver IGF-I mRNA and Liver Growth Hormone Receptor mRNA in Food-Deprived Cattle. J Nutr 133, 2555-2560

Wiener G, Han JL, Long RJ (2003) Origins, domestication and distribution of yak, and production characteristics of yak. In: The Yak. 2nd ed. Regional Office for Asia and the Pacific of the Food and Agriculture Organization of the United Nations, Bangkok, Thailand, 136-137

Yakar S, Liu JL, Stannard B, Butler A, Accili D, Sauer B, LeRoith D (1999) Normal growth and development in the absence of hepatic insulin-like growth factor I. Proc Natl Acad Sci U S A 96, 7324-7329

Zhang X, Ho SM (2011) Epigenetics meets endocrinology. J Mol Endocrinol 46, R11-R32

Zuker M (2003) Mfold web server for nucleic acid folding and hybridization prediction. Nucleic Acids Res 31, 3406-3415 